\title{
Ginsenoside Rg1 enhances the resistance of hematopoietic stem/progenitor cells to radiation- induced aging in mice
}

\author{
Cui $\mathrm{CHEN}^{1}$, Xin-yi MU ${ }^{1}$, Yue ZHOU ${ }^{3}$, Ke SHUN ${ }^{1}$, Shan GENG ${ }^{1}$, Jun LIU $^{1}$, Jian-wei WANG ${ }^{1}$, Jie CHEN ${ }^{2}$, Tin-yu LI ${ }^{2}$, Ya-ping WANG ${ }^{1, *}$ \\ ${ }^{1}$ Laboratory of Stem Cells and Tissue Engineering, Department of Histology and Embryology, Chongqing Medical University, Chongqing \\ 400016, China; ${ }^{2}$ Chongqing Stem Cell Therapy Engineering Technical Center, Chongqing 400016, China; ${ }^{3}$ Department of Histology and \\ Embryology, Dali University, Dali 671000, China
}

\begin{abstract}
Aim: To investigate the effects of ginsenoside Rg1 on the radiation-induced aging of hematopoietic stem/progenitor cells (HSC/HPCs) in mice and the underlying mechanisms.

Methods: Male C57BL/6 mice were treated with ginsenoside Rg1 (20 $\mathrm{mg} \cdot \mathrm{kg}^{-1} \cdot \mathrm{d}^{-1}$, ip) or normal saline (NS) for $7 \mathrm{~d}$, followed by exposure to 6.5 Gy X-ray total body irradiation. A sham-irradiated group was treated with NS but without irradiation. Sca- $1^{+}$HSC/HPCs were isolated and purified from their bone marrow using MACS. DNA damage was detected on d 1 . The changes of anti-oxidative activities, senescence-related markers senescence-associated $\beta$-galactosidase (SA- $\beta$-gal) and mixed colony-forming unit (CFU-mix), P16 ${ }^{\text {INK4a }}$ and P21 ${ }^{\text {Cip1/Waf1 }}$ expression on $d 7$, and cell cycle were examined on $d 1, d$, and $d 7$.

Results: The irradiation caused dramatic reduction in the number of Sca- $1^{+} \mathrm{HSC} / \mathrm{HPCs}$ on $\mathrm{d} 1$ and the number barely recovered until d 7 compared to the sham-irradiated group. The irradiation significantly decreased SOD activity, increased MDA contents and caused DNA damage in Sca- $1^{+}$HSC/HPCs. Moreover, the irradiation significantly increased SA- $\beta$-gal staining, reduced CFU-mix forming, increased the expression of $\mathrm{P} 16^{\mathrm{INK} 4 a}$ and $\mathrm{P} 21^{\mathrm{Cip} 1 / \text { Waf1 }}$ in the core positions of the cellular senescence signaling pathways and caused $\mathrm{G}_{1}$ phase arrest of Sca- $1^{+}$HSC/HPCs. Administration of ginsenoside Rg1 caused small, but significant recovery in the number of Sca- $1^{+}$ HSC/HPCs on d 3 and d 7. Furthermore, ginsenoside Rg1 significantly attenuated all the irradiation-induced changes in Sca- $1^{+}$HSC/ HPCs, including oxidative stress reaction, DNA damage, senescence-related markers and cellular senescence signaling pathways and cell cycle, etc.
\end{abstract}

Conclusion: Administration of ginsenoside Rg1 enhances the resistance of HSC/HPCs to ionizing radiation-induced senescence in mice by inhibiting the oxidative stress reaction, reducing DNA damage, and regulating the cell cycle.

Keywords: ginsenoside Rg1; hematopoietic stem and progenitor cell (HSC/HPC); ionizing radiation; cellular senescence; oxidative stress; DNA damage; cell cycle

Acta Pharmacologica Sinica (2014) 35: 143-150; doi: 10.1038/aps.2013.136; published online 16 Dec 2013

\section{Introduction}

With the growing population, aging, extended lifespans, and anti-aging have become popular areas of research in life and social sciences. Studies have shown that tissue-specific stem cells replaces worn out and damaged cells to maintain the internal environment homeostasis of a normal body ${ }^{[1,2]}$. It has been proposed that the aging of an organism is actually due to the senescence of these stem cells. Studies have also shown that hematopoietic stem cell (HSC) senescence is closely relative to aging and senile diseases ${ }^{[2-4]}$. Exploring the mechanism

* To whom correspondence should be addressed.

E-mail ypwangcq@aliyun.com

Received 2013-05-05 Accepted 2013-08-28 of HSC senescence and anti-senescence provides the foundations for possible methods to delay aging.

Ginseng has been used to enhance stamina and the body's capacity to address fatigue and physical stress for thousands of years in Chinese medical science and is now commonly used around the world. Ginsenoside Rg1 is an active ingredient in ginseng, and this compound plays roles in anti-aging and anti-oxidation, as well as improves immunity and memory $^{[5,6]}$.

It has been reported that ionizing radiation causes acute tissue damage and long-term bone marrow injury, including DNA damage, which primarily contributes to the senescence, impaired self-renewal and reduced pluripotency of $\mathrm{HSCs}^{[7,8]}$. In the present study, we induced HSC senescence by ionizing 
radiation in an in vivo mouse model and investigated the antiaging mechanism of ginsenoside Rg1 to provide foundations for possible ways to delay aging.

\section{Materials and methods Animals}

Male C57BL/6 mice, 6-8 weeks old, were purchased from the Medical and Laboratory Animal Center of Chongqing and housed in a temperature- and light-controlled room with free access to water and food. All experiments were performed in accordance with the institutional and national guidelines and regulations and approved by the Chongqing Medical University Animal Care and Use Committee.

Ninety-nine mice were randomly divided into three groups: 1) the irradiated $+\operatorname{Rg} 1$ group , 2) the irradiated group and 3) the sham-irradiated control group. In the irradiated $+\operatorname{Rg} 1$ group and the irradiated group, mice were treated with ginsenoside Rg1 (20 mg $\mathrm{kg}^{-1} \cdot \mathrm{d}^{-1}$, intraperitoneally) or normal saline in the same volume for $7 \mathrm{~d}$, followed by exposure to $6.5 \mathrm{~Gy}$ X-ray total body irradiation, which was delivered by a linear accelerator (Philips, SL75-14, UK) at a dose rate of $57.28 \mathrm{~Gy} / \mathrm{min}$; the irradiator was placed $75 \mathrm{~cm}$ from the target, and an irradiation field of $20 \mathrm{~cm} \times 20 \mathrm{~cm}$ was used. The interval time between the last injection and irradiation was $24 \mathrm{~h}$. In the sham-irradiated control group, the mice were injected with NS and were not subjected to irradiation.

\section{Reagents}

Ginsenoside Rg1 (purity $>95 \%$ ) was purchased from Hongiu Biotech Co, Ltd (Tonghua, China). IMDM medium, fetal bovine serum (FBS) and equine serum (ES) were purchased from Gibco (CA, USA). The Anti-Sca- $1^{+}$Micro Bead kit was obtained from Miltenyi Biotech Co (Bergisch Gladbach, Germany), and the SA- $\beta$-gal Staining kit was purchased from Cell Signaling (Boston, USA). The CFU-mix culture media were purchased from Stem Cell Co (CA, USA), whereas the SOD and MDA kits were purchased from Nanjing Jiancheng Bioengineering Institute (Nanjing, China). The comet assay kit was purchased from Research Bio-Lab Co, Ltd (Beijing, China). Anti-P16 ${ }^{\mathrm{INK4a}}$ antibody, anti-P21 ${ }^{\mathrm{Cip} 1 / \text { Waf1 }}$ antibody and goat antirabbit antibody were obtained from Santa Cruz (CA, USA).

\section{Isolation and purification of Sca-1 $\mathbf{1}^{+}$HSCs from the mouse bone} marrow

The mice were sacrificed by cervical dislocation, and the femurs were collected. A single-cell suspension of the bone marrow was obtained. HSCs positive for stem cell antigen 1 $\left(\mathrm{Sca}-1^{+}\right)$were isolated and purified by MACs as previously described $^{[9]}$. The numbers of Sca- $1^{+}$HSC/HPCs in each group were analyzed.

\section{Detection of senescence-associated markers in the Sca- $1^{+}$HSC/ HPCs}

Senescence-associated $\beta$-galactosidase cytochemical staining

The Sca- $1^{+}$HSC/HPCs were collected on d 7 following TBI, and the senescence-associated $\beta$-galactosidase (SA- $\beta$-gal) staining was carried out according to the manufacturer's instructions (Cell Signaling). Briefly, $1 \times 10^{5}$ purified cells were washed twice with PBS, fixed in Fixative Solution for $10 \mathrm{~min}$ at room temperature, and stained with Staining Solution for $12 \mathrm{~h}$ at $37^{\circ} \mathrm{C}$ without $\mathrm{CO}_{2}$. Approximately $1 \times 10^{4}$ cells were separated on each slide, and 400 cells were totally analyzed for each group. The percentage of SA- $\beta$-gal-positive cells was calculated by counting the number of blue cells under the bright field illumination, and then dividing by the total number of cells.

\section{Mixed colony-forming unit (CFU-Mix) of HSC/HPC culture}

The Sca- $1^{+}$HSC/HPCs were collected on d 7 following TBI. The mixed colony-forming unit (CFU-mix) culture was performed as previously described ${ }^{[9]}$. Briefly, $1 \times 10^{4}$ Sca $-1^{+} \mathrm{HSC} /$ HPCs were mixed with 2-mercaptoethanol $\left(1 \times 10^{-4} \mathrm{~mol} / \mathrm{L}\right), 3 \%$ L-glutamine, ES, rhEPO, IL-3 and rhGM-CSF in a final volume of $2 \mathrm{~mL}$, and the cells were plated in 96-well plates and grown in a humidified atmosphere with $5 \% \mathrm{CO}_{2}$ at $37^{\circ} \mathrm{C}$ for $7 \mathrm{~d}$. The number of CFU-Mix represents the pluripotency of the Sca- $1^{+}$ HSC/HPCs.

\section{The detection of SOD activity and MDA content}

The Sca- $1^{+}$HSC/HPC cells $\left(1 \times 10^{6}\right)$ from each group were collected on $\mathrm{d} 7$ following TBI and lysed in an ice bath for $30 \mathrm{~min}$. The supernatant was collected after centrifugation. SOD activity and MDA content were detected by chemical colorimetric analysis according to the manufacturer's instructions.

\section{Single cell gel electrophoresis (comet assay)}

The Sca- $1^{+}$HSC/HPCs in each group were collected on the $\mathrm{d} 1$ following TBI, and $30 \mu \mathrm{L}$ of the cell suspension was transferred on agarose-coated slides. The slides were placed in cold lysis buffer for $2 \mathrm{~h}$ and then incubated with proteinase $\mathrm{K}$ for $2 \mathrm{~h}$. The DNA was denatured by electrophoresis and stained with ethidium bromide. The slides were examined under a fluorescent microscope. The comet parameters including the olive tail moment, and the tail lengths were measured and analyzed using the Comet A software to evaluate DNA damage.

\section{RNA extraction and semi-quantitative RT-PCR}

The Sca- $1^{+}$HSC/HPCs $\left(1 \times 10^{6}\right)$ from each group were collected on $\mathrm{d} 7$ following TBI. Total mRNA was extracted using the TRIzol Reagent (TaKaRa, Japan), according to the manufacturer's protocol. The $O D_{260} / O D_{280}$ ratio of the RNA was between 1.8 and 2.0. Changes in expression were verified by RT-PCR for $\mathrm{p} 16^{\mathrm{INK4a}}$ and $\mathrm{p} 21^{\mathrm{Cip} 1 / \text { Waf1 }}$, which play important roles in cell cycle regulation. The unique PCR primers are shown in Table 1. First-strand cDNA was performed using RT (TaKaRa, Japan). The DNA was amplified by an initial incubation at $94^{\circ} \mathrm{C}$ for $2 \mathrm{~min}$, followed by 35 cycles of $94^{\circ} \mathrm{C}$ denaturation for $30 \mathrm{~s}$, annealing at $58^{\circ} \mathrm{C}$ for $40 \mathrm{~s}$, and $72^{\circ} \mathrm{C}$ extension for $40 \mathrm{~s}$. GAPDH served as an internal standard. The PCR products were separated by electrophoresis in a 1\% agarose gel. The optical intensities were quantified using Quantity One (Bio-Rad). The relative expression levels were calculated as 
Table 1. Primers sequences.

\begin{tabular}{llll}
\hline Primer & \multicolumn{1}{c}{ Forward $\left(5^{\prime}-3^{\prime}\right)$} & Reverse $\left(5^{\prime}-3^{\prime}\right)$ & Size $(\mathrm{bp})$ \\
\hline p16 & & \\
p21 $21^{\text {lip } 1 / \text { Waf } 1}$ & TCCGCTGCAGACAGACTGGCCAG & CATCGCGCACATCCAGCCGAGC & 295 \\
gapdh & ATTCCTGGTGATGTCCGACC & AAAGTTCCACCGTTCTCGG & 144 \\
\hline
\end{tabular}

the ratio of the optical intensity of the target gene to that of GAPDH.

\section{Western blotting analysis}

The Sca- $1^{+}$HSC/HPCs in each group were collected on d 7 following TBI. Total protein was extracted, and the concentration was measured using the BCA procedure. Samples containing $50 \mu \mathrm{g}$ of protein were separated by SDS-PAGE and transferred to PVDF membranes. The membranes were incubated overnight at $4^{\circ} \mathrm{C}$ with the $\mathrm{P} 16^{\mathrm{INK} 4 \mathrm{a}}$ antibody or P21 ${ }^{\mathrm{Cip} 1 / \text { Waf1 }}$ antibody at a 1:400 dilution. The secondary antibody was diluted 1:5000 in TBST. The membranes were visualized using the enhanced chemiluminescence detection system (Pierce). The level of $\beta$-actin was used as an internal control. The relative intensities were quantified using Quantity One (Bio-Rad).

\section{FCM measurement of cell cycle}

The Sca- $1^{+}$HSC/HPC cells from each group were collected on d 1, d 3, and d 7 following TBI and were fixed with $70 \%$ icecold ethanol overnight. The fixed cells were then incubated with $100 \mu \mathrm{L}$ of bovine pancreatic ribonuclease $(1 \mathrm{mg} / \mathrm{mL})$ at $37^{\circ} \mathrm{C}$ for $30 \mathrm{~min}$, followed by incubation with PI $(1 \mu \mathrm{g} / \mathrm{mL})$ for another $30 \mathrm{~min}$ in the dark. The PI fluorescence was excited at a wavelength of $488 \mathrm{~nm}$, and the emission was detected at 610 $\mathrm{nm}$. The PI fluorescence of individual nucleus was measured by flow cytometry (FCM, FACS Vantage SE, BD), and $\geq 2 \times 10^{4}$ cells were analyzed for each sample. The proportions of the cells in each cell cycle phase were determined using the PCLysys II software.

\section{Statistical analysis}

The data were analyzed by ANOVA using the SPSS version 13.0 software and represented as mean $\pm S D$. Differences were considered significant if $P<0.05$.

\section{Results}

The effect of ginsenoside Rg1 on the number of Sca- $1^{+} \mathrm{HSC} /$ HPCs

TBI was carried out on d 0 . After the Sca- $1^{+}$HSC/HPCs were isolated and purified from mouse bone marrow cells by MACS, the purity of the cells was found to be $93.66 \%$, and the survival of the separated cells was $99.4 \%$ according to the Trypan blue dye exclusion assay. In the irradiated group, the number of Sca- $1^{+}$HSC/HPCs was violently reduced on d 1, bottomed out on d 3 , and had barely recovered by d 7, compared to the sham-irradiated control group. However, in the irradiated+Rg1 group, the number of Sca- $1^{+} \mathrm{HSC} / \mathrm{HPC}$ also violently decreased $1 \mathrm{~d}$ after irradiation, but began to notably recover on $\mathrm{d} 3$ and had remarkably recovered by d 7 (Figure $1)$. Moreover, there were no notable differences between the groups before TBI (d 0).

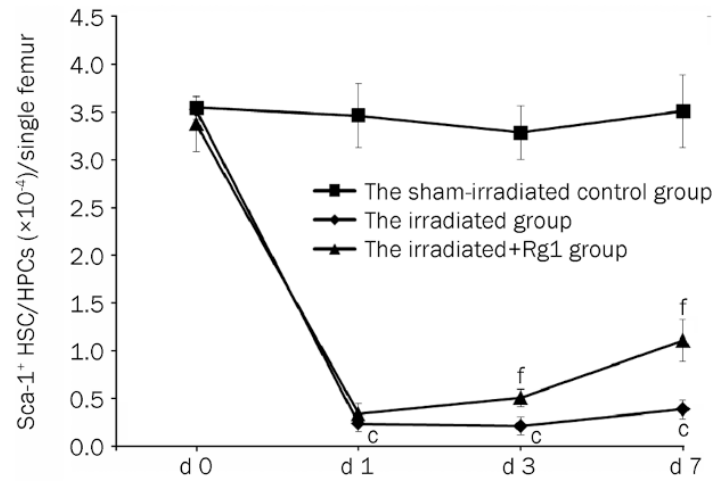

Figure 1. The effect of ginsenoside Rg1 on the number of Sca- $1^{+} \mathrm{HSC} /$ HPCs per femur of irradiated mouse ( $\mathrm{d} 0 n=3$, others $n=10$ ). Mice were excuted at the desired time. The femurs were collected and the Sca- $1^{+}$ HSCs were isolated. The number of the HSC/HPCs in each group were analyzed. Data in d 0 represents cells colleceted before TBI. ${ }^{\mathrm{c}} P<0.01 \mathrm{vs}$ the sham-irradiated control group. ${ }^{\mathrm{f}} P<0.01$ vs the irradiated group.

The effect of ginsenoside Rg1 on the senescence of purified Sca- $1^{+}$HSC/HPCs from irradiated mice

SA- $\beta$-gal is one of the most widely used biomarkers for aging cells $^{[10]}$. Therefore, we performed SA- $\beta$-gal staining to investigate the effect of Rg1 on irradiation-induced Sca- $1^{+} \mathrm{HSC} /$ HPC senescence. As shown in Figure 2A, the aged cells are stained in blue in the cytoplasm. Moreover, the capacity to form CFU-Mix can evaluate the senescence of HSCs, and this ability decreased with the senescence of the HSCs. Therefore, we also performed CFU-mix culture and counted the numbers of mixed hematopoietic progenitor colonies (Figure 2B).

The Sca- $1^{+}$HSC/HPCs were collected on $\mathrm{d} 7$ following TBI. Irradiation induced a remarkable increase in the percentage of cells stained positive for SA- $\beta$-gal (Figure 2A, Table 2) and a significant decrease in the number of CFU-mix formed by the Sca- $1^{+}$HSCs, compared to the sham-irradiated control group (Figure 2B, Table 2). However, in the irradiated+Rg1 group, the proportion of SA- $\beta$-gal positive HSC/HPCs was significantly reduced (Figure $2 \mathrm{~B}$, Table 2 ) and the number of CFU-mix was remarkably increased, as well as the number of colony forming cells, compared to the irradiated group (Figure 
A SA-B-stainning

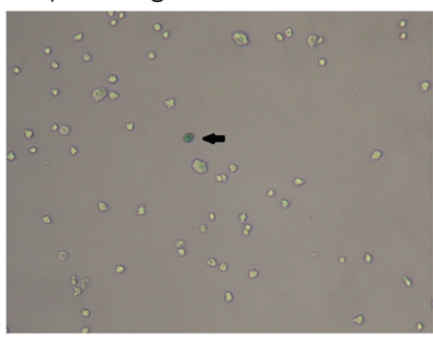

The sham-irradiated control group $(\times 200)$

B CFU-mix

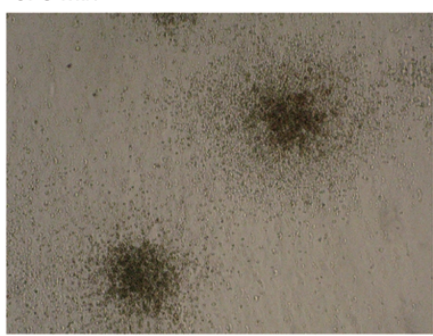

The sham-irradiated control group $(\times 200)$

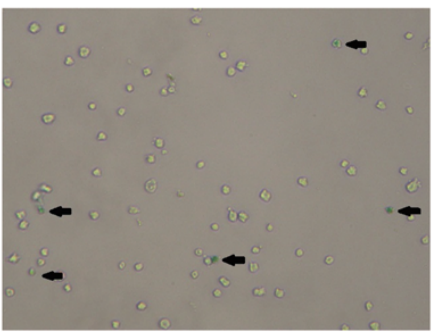

The irradiated group $(\times 200)$

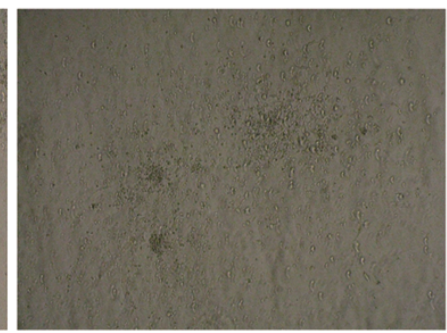

The irradiated group $(\times 200)$

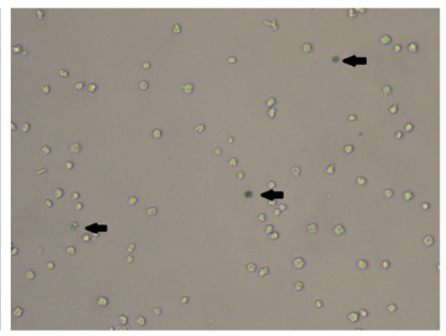

The irradiated+Rg1 group $(\times 200)$

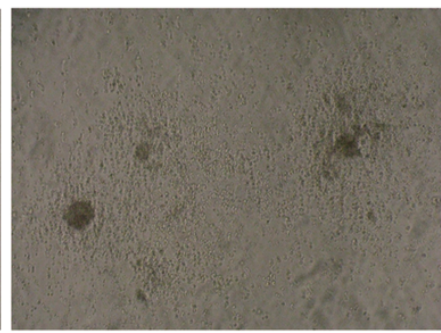

The irradiated+Rg1 group $(\times 200)$

C

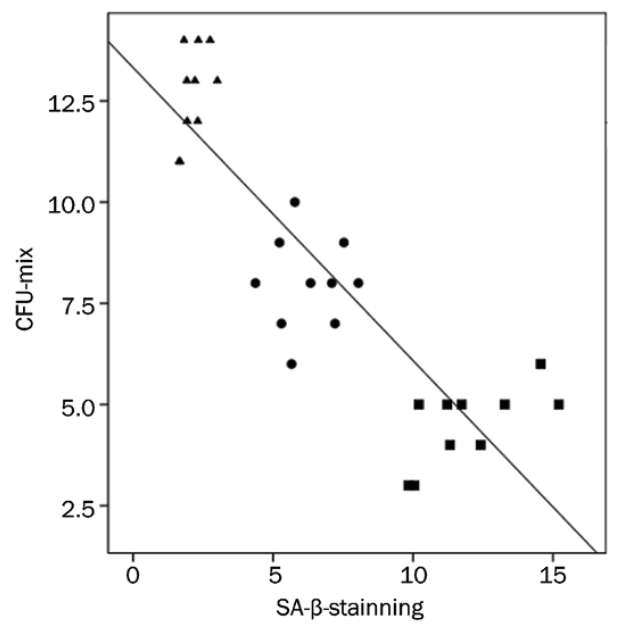

X-ray

- The sham-irradiated control group

- The irradiated group

- The irradiated+Rg1 group

-Fit line for total

$\mathrm{R}^{2}$ linear $=0.752$

Figure 2. The effect of ginsenoside Rg1 on the Sca- $1^{+}$HSC/HPCs senescence of irradiated mouse. The Sca- $1^{+}$HSC/HPCs were collected on d 7 following TBI. (A) The senescence-associated $\beta$-galactosidase (SA- $\beta$-gal) staining was carried out. The aged cells are stained in blue in the cytoplasm (arrow). (B) The the capacity of Sca- $1^{+}$HSC/HPCs to form hematopoietic progenitor colonies were evaluated by CFU-mix culture. (C) The correlation analysis between the percentage of $\mathrm{SA}-\beta$-gal positive cells and the number of CFU-mix.

Table 2. The effect of ginsenoside Rg1 on SA- $\beta$-gal staining and CFU-mix forming of Sca- $1^{+}$HSC/HPCs in the irradiated mice (mean \pm SD, $n=10$ ). ${ }^{\mathrm{c}} P<0.01$ vs the sham-irradiated control group. ${ }^{\mathrm{f}} P<0.01$ vs the irradiated group.

\begin{tabular}{lcc}
\hline Group & $\begin{array}{c}\text { The percentage of } \\
\text { SA- } \beta \text {-gal positive } \\
\text { cells }(\%)\end{array}$ & $\begin{array}{c}\text { The number of } \\
\text { CFU-Mix (per 10 } \\
\text { Sca- }{ }^{+} \text {HSC/HPCs) }\end{array}$ \\
\hline The sham-irradiated control group & $2.16 \pm 0.45$ & $12.70 \pm 1.16$ \\
The irradiated group & $11.99 \pm 1.87^{\circ}$ & $4.50 \pm 0.97^{\circ}$ \\
The irradiated+Rg1 group & $6.26 \pm 1.18^{\dagger}$ & $8.00 \pm 1.15^{\dagger}$ \\
\hline
\end{tabular}

2B, Table 2). Furthermore, we performed correlational analyses and found a negative correlation existing between the positive rate of SA- $\beta$-gal and the number of CFU-mix $(R=0.867)$ (Figure 2C).

\section{The effect of ginsenoside Rg1 on the SOD activity and MDA} content of the Sca- $1^{+}$HSC/HPCs from irradiated mice

Superoxide dismutase (SOD) is responsible for the degeneration of reactive oxygen species (ROS), which can cause cells to senesce. Malondialdehyde (MDA), a product of ROS, can be used as an oxidative stress biomarker. By measuring the SOD activity and MDA content of cells, we determined the anti- 
oxidant ability and oxidative damage of the HSC/HPCs.

The Sca- $1^{+}$HSC/HPC cells $\left(1 \times 10^{6}\right)$ from each group were collected on $\mathrm{d} 7$ following TBI. Compared to the shamirradiated control group, SOD activity decreased and MDA content increased in the Sca- $1^{+}$HSC/HPCs in the irradiated group. Meanwhile, Rg1 partially rescued the reduction of SOD activity, leading to a decrease in MDA content in the irradiated+Rg1 group (Table 3).

Table 3. The effect of ginsenoside Rg1 on the activity of SOD and the content of MDA of Sca- $1^{+}$HSC/HPCs in the irradiated mice (mean $\pm S D, n=10$ ). ${ }^{\mathrm{c}} P<0.01$ vs the sham-irradiated control group. ${ }^{\mathrm{f}} P<0.01$ vs the irradiated group.

\begin{tabular}{lcc}
\hline \multicolumn{1}{c}{ Group } & $\begin{array}{c}\text { The activity of SOD } \\
(\mathrm{U} / \mathrm{mL})\end{array}$ & $\begin{array}{c}\text { MDA } \\
(\mathrm{nmol} / \mathrm{mg} \text { prot })\end{array}$ \\
\hline The sham-irradiated control group & $\begin{array}{l}27.19 \pm 3.50 \\
19.24 \pm 2.52^{\mathrm{C}}\end{array}$ & $\begin{array}{l}2.50 \pm 0.48 \\
6.34 \pm 1.07^{\mathrm{c}} \\
\text { The irradiated group }\end{array}$ \\
The irradiated+Rg1 group & $24.48 \pm 3.02^{\mathrm{f}}$ & $4.21 \pm 0.44^{\mathrm{f}}$ \\
\hline
\end{tabular}

The effect of ginsenoside Rg1 on the DNA damage of Sca-1 ${ }^{+}$ HSC/HPCs in irradiated mice

The comet assay was used to determine the DNA damage present in the cells. This damage is mostly expressed by the length of the comet tail and the Olive moment. The Sca- $1^{+}$ HSC/HPCs in each group were collected on the $\mathrm{d} 1$ following TBI. Spherical and intact nuclei from Sca- $1^{+}$HSC/HPC cells were observed in the sham-irradiated control group, while the nucleus was observed as a bright orange head with a long comet tail in the irradiated group. In the irradiated+Rg1 group, the comet tails were smaller than those of the irradiated group (Figure 3). A computerized system was used to further analyze these samples. As expected, the comet tail length and the Olive moment of the irradiated group were both significant larger than those of the sham-irradiated control group. Meanwhile, in the irradiated+Rg1 group, the injection of ginsenoside Rg1 resulted in a remarkably smaller comet tail length and the Olive moment than the irradiated group (Table 4).
Table 4. The effect of ginsenoside Rg1 on the DNA damage of Sca- $1^{+}$ HSC/HPCs in the irradiated mice (mean \pm SD, $n=10$ ). ${ }^{\circ} P<0.01$ vs the shamirradiated control group. ${ }^{\mathrm{f}} P<0.01$ vs the irradiated group.

\begin{tabular}{lcc}
\hline \multicolumn{1}{c}{ Group } & Tail length $(\mu \mathrm{m})$ & Olive moment \\
\hline The sham-irradiated control group & $4.42 \pm 2.97$ & $1.24 \pm 1.10$ \\
The irradiated group & $90.54 \pm 21.67^{\circ}$ & $53.09 \pm 19.11^{\circ}$ \\
The irradiated+Rg1 group & $47.21 \pm 8.01^{\dagger}$ & $22.15 \pm 7.50^{\dagger}$ \\
\hline
\end{tabular}

The effect of ginsenoside Rg1 on the expression of P16 ${ }^{\text {INK4a }}$ and P21 ${ }^{\text {Cip1/Waf1 }}$

The P16 ${ }^{\mathrm{INK} 4 \mathrm{a}}$-retinoblastoma $(\mathrm{Rb})$ pathway and the P19 ${ }^{\mathrm{Arf}}$ Mdm2-P53-P21 ${ }^{\text {Cip1/Waf1 }}$ pathway are two main signal transduction pathways involved in cell aging processes. Therefore, we performed RT-PCR and Western blot analyses to explore the mRNA and protein expressions, respectively, of $\mathrm{P} 16^{\mathrm{INK} 4 \mathrm{a}}$ and $\mathrm{P} 21^{\mathrm{Cip} 1 / \text { Waf1 }}$, which are located in the core positions of the two senescence-associated pathways. The expression of GAPDH and $\beta$-actin were used as the internal controls for the mRNA and western blot analyses, respectively. The mRNA of Sca- $1^{+}$ HSC/HPCs $\left(1 \times 10^{6}\right)$ from each group were collected on day 7 following TBI. As shown in Figure 4 and Table 5, both the mRNA and protein expression of $\mathrm{P} 16^{\mathrm{INK} 4 \mathrm{a}}$ and $\mathrm{P} 21^{\mathrm{Cip} 1 / \text { Waf1 }}$ were significantly higher in the irradiated group than in the shamirradiated control group. In the irradiated+Rg1 group, both the mRNA and protein expression of P16 ${ }^{\mathrm{INK} 4 \mathrm{a}}$ and P21 $1^{\text {Cip1/Waf1 }}$ were significantly lower than that of the irradiated group.

The effect of ginsenoside Rg1 on the cell cycle distribution of Sca- $1^{+}$HSC/HPCs in irradiated mice

Because P16 ${ }^{\text {INK4a }}$ and P21 ${ }^{\text {Cip1/Waf1 }}$ play roles in cell cycle regulation and because cells are arrested at the $\mathrm{G}_{1}$ stage when HSCs age ${ }^{[11]}$, we examined the cell cycle profile of these cells using FACS. The Sca- $1^{+} \mathrm{HSC} / \mathrm{HPC}$ cells from each group were collected on d 1, d 3, and d 7 following TBI respectively. In both the irradiated group and the irradiated+Rg1 group, the Sca- $1^{+}$ HSC/HPCs displayed a $\mathrm{G}_{1}$ phase arrest, and the percentages of cells in $S$ and $M$ phases was significantly decreased compared to the sham-irradiated control group on d 1. However, the $G_{1}$ arrest was barely overcome in the irradiated group, while the number of irradiated+Rg1 cells arrested at in $G_{1}$
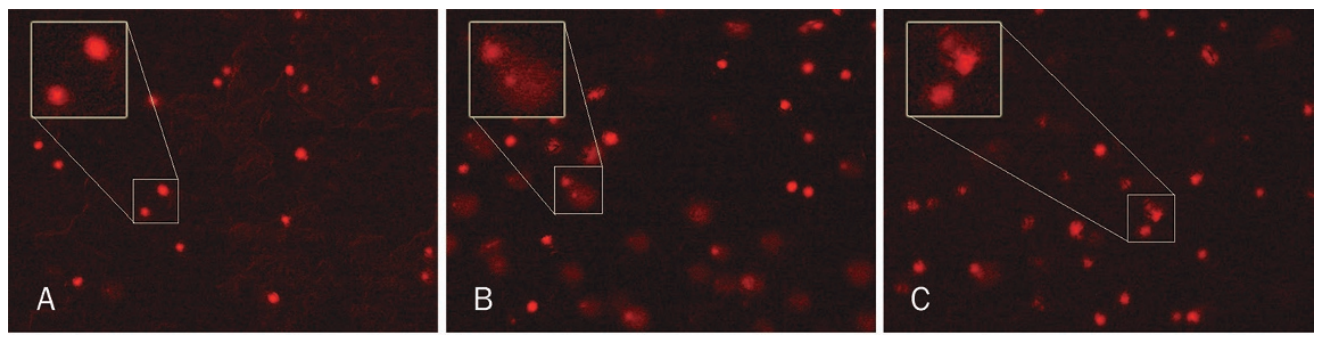

Figure 3. The effect of ginsenoside Rg1 on the DNA damage of Sca- $1^{+} \mathrm{HSC} / \mathrm{HPC}$ in the irradiated mice. The Sca- $1^{+} \mathrm{HSC} / \mathrm{HPCs}$ in each group were collected on the $\mathrm{d} 1$ following TBI. The comet assay was used to determine the DNA damage present in the cells. Enlarged images shown in the left top corner are from the framed region. (A) The sham+irradiated control group $(\times 100)$. (B) The irradiated group $(\times 100)$. (C) The irradiated+Rg1 group $(\times 100)$. 

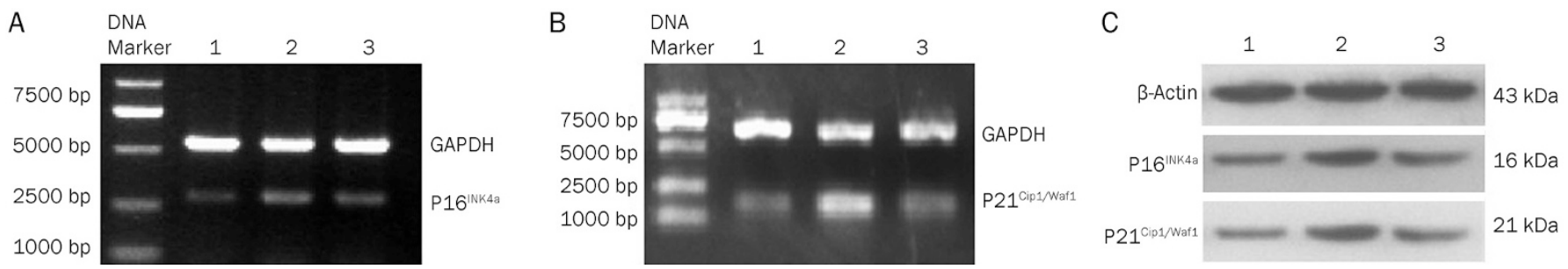

Figure 4. The effect of ginsenoside Rg1 on the mRNA and protein expression of $p 16^{\text {INK4a }}$ and $p 21^{\text {Cip } 1 / \text { Waf1 }}$ in the irradiated mice. The mRNA of Sca- $1^{+}$ HSC/HPCs $\left(1 \times 10^{6}\right)$ from each group were collected on $d 7$ following TBI. Gapdh was used as the internal control. The experiments were performed three times with similar results. (A) The sham+irradiated control group. (B) The irradiated group. (C) The irradiated+Rg1 group.

Table 5. The effect of ginsenoside Rg1 on the mRNA and protein expression of $p 16^{\mathrm{INK} 4 \mathrm{a}}$ and $p 21^{\mathrm{Cip} 1 / \text { waf1 }}$ in the irradiated mice (mean $\pm \mathrm{SD}, \mathrm{n}=10$ ). ${ }^{c} P<0.01$ vs the sham-irradiated control group. ${ }^{f} P<0.01$ vs the irradiated group.

\begin{tabular}{|c|c|c|c|c|}
\hline \multirow[t]{2}{*}{ Group } & \multicolumn{2}{|c|}{ mRNA expression } & \multicolumn{2}{|c|}{ Protein expression } \\
\hline & $P 16^{\mathrm{INK} 4 \mathrm{a}} / \mathrm{GAPDH}$ & $P 21^{\text {Cip } 1 / \text { Waf1 }} /$ GAPDH & $\mathrm{P} 16^{\mathrm{INK} 4 \mathrm{a}} / \beta$-actin & $\mathrm{P} 21^{\mathrm{Cip} 1 / \text { Waf } 1 / \beta \text {-actin }}$ \\
\hline The sham-irradiated control group & $0.489 \pm 0.032$ & $0.457 \pm 0.032$ & $0.224 \pm 0.013$ & $0.309 \pm 0.014$ \\
\hline The irradiated group & $0.802 \pm 0.041^{\mathrm{c}}$ & $0.789 \pm 0.045^{c}$ & $0.831 \pm 0.037^{c}$ & $0.823 \pm 0.033^{c}$ \\
\hline The irradiated+Rg1 group & $0.673 \pm 0.033^{f}$ & $0.621 \pm 0.029^{f}$ & $0.613 \pm 0.024^{f}$ & $0.578 \pm 0.027^{f}$ \\
\hline
\end{tabular}

phase was significantly reduced on d 3 and d 7 (Figure 5).

\section{Discussion}

The effect of ginsenoside Rg1 on the senescence of Sca- $1^{+}$HSC/ HPCs

HSC/HPCs are a type of stem cells that has high self-renewal capacity and multi-lineage differentiation potential. They continuously proliferate and differentiate via unequal division to maintain the homeostasis of the peripheral blood cells. It has been reported that ionizing radiation causes HSCs damage, induces cells senescence and apoptosis, and results in the loss of the hematological-reconstitution function ${ }^{[7,8]}$.

In this study, the number of Sca- $1^{+}$HSC/HPCs was violently reduced following exposure to $6.5 \mathrm{~Gy}$ X-ray TBI, and these levels barely recovered; however, in the irradiated+Rg1 group, a notable increase in the number of cells was observed on $\mathrm{d} 3$ (Figure 1). This result suggests that ionizing irradiation is fatal to HSC/HPCs, but ginsenoside Rg1 can help restore the HSC/HPCs.

Furthermore, multiple aging indexes were used to evaluate the effect of $\operatorname{Rg} 1$ on the senescence of the surviving Sca- $1^{+}$ HSC/HPCs. SA- $\beta$-gal, which reflects the function of the lysosomes, accumulates in aging cells as the lysosomes begin to malfunction. The capacity to form CFU-mix colonies decreases with the regression of self-renewal and multi-differentiation potential in aging HSCs and is another widely used biomarker for HSC/HPC senescence ${ }^{[12]}$.

In the present study, we found that the proportion of SA- $\beta$ gal positive HSC/HPCs was significantly increased (Figure 2A, Table 2) and the number of CFU-mix and colony form-
A

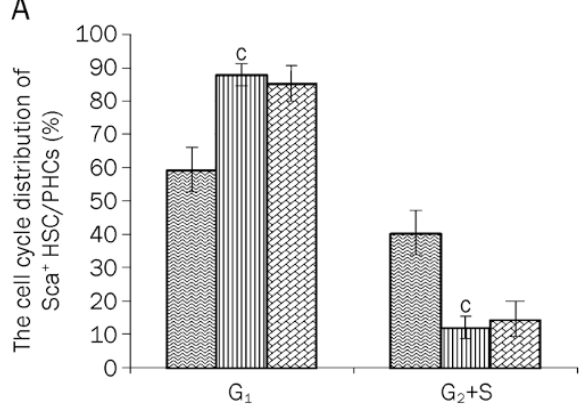

B

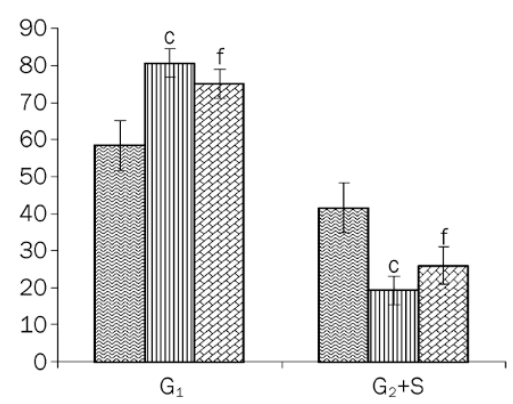

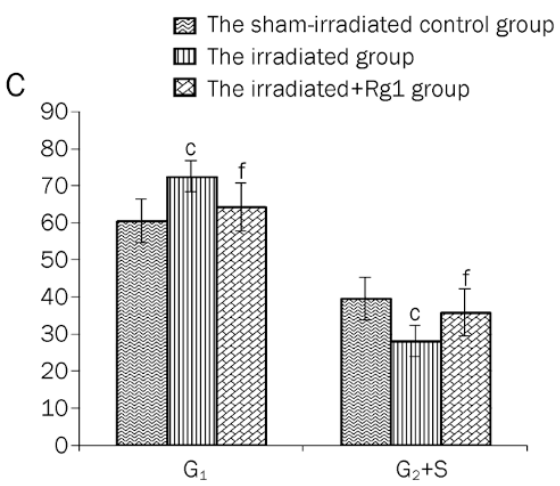

Figure 5. The effect of ginsenoside Rg1 on the cell cycle distribution of Sca- $1^{+} \mathrm{HSC} / \mathrm{HPCs}$ in the irradiated mice $(n=10)$. The Sca- $1^{+} \mathrm{HSC} / \mathrm{HPC}$ cells from each group were collected on d 1 (A), d $3(B)$, and d 7 (C) following TBI. Cell cycle was measured by flow cytometry, and $\geq 2 \times 10^{4}$ cells were analyzed for each sample. ${ }^{\mathrm{C}} P<0.01$ vs the sham-irradiated control group. ${ }^{\mathrm{f}} P<0.05$ vs the irradiated group. 
ing cells were remarkably reduced in the irradiated group. However, daily injection of ginsenoside Rg1 partially reversed these irradiation-induced, senescence-associated index changes. Further analysis showed a negative correlation existing between the positive rate of SA- $\beta$-gal accumulation and the number of CFU-mix cells. These results are consistent with previous studies that showed HSCs senescence is accompanied by a regression of self-renewal and multi-differentiation potential ${ }^{[12]}$. These results suggested that ginsenoside Rg1 was able to counteract the persistent senescence of the HSC/HPCs induced by irradiation.

\section{The effect of ginsenoside Rg1 on the oxidative stress and DNA} damage of Sca-1 $\mathbf{1}^{+}$HSC/HPCs in irradiated mice

Irradiation induces an abnormal generation of reactive oxygen species (ROS), which causes intercellular oxidative damage and results in cell senescence. It has been reported that aberrant increases in ROS can disrupt HSC quiescence by stimulating entry into the cell cycle, which comprises the ability of the HSCs to self-renew and leads to premature exhaustion ${ }^{[13-15]}$. Superoxide dismutase (SOD) is an enzyme that catalyzes the dismutation of superoxide into oxygen and hydrogen peroxide. Thus, it is an important anti-oxidant defense enzyme in nearly all cells. ROS degrades polyunsaturated lipids, thereby forming malondialdehyde (MDA). The production of MDA is used as a biomarker to measure the level of oxidative stress in an organism. MDA levels increase continuously with cell age, so this biomarker also reflects cellular senescence. By measuring the SOD activity and MDA content of the cells, we determined the anti-oxidant ability and oxidative damage of the HSC/HPCs.

We found that SOD activity decreased and MDA content increased in the Sca- $1^{+}$HSC/HPCs following TBI. These results demonstrated that irradiation reduced SOD activity and resulted in oxidative damages in the Sca- $1^{+}$HSC/HPCs. Several studies have shown that ginsenoside Rg1 treatment increases SOD activity in neurons, livers and lungs ${ }^{[16-18]}$. Similarly, in the present study, ginsenoside Rg1 partially rescued the reduction of SOD activity and increase in MDA content. This suggests that ginsenoside Rg1 can improve the activity of SOD, which is important in the breakdown of ROS, to prevent HSC/HPCs from irradiation-induced oxidative stress. However, the mechanism by which ginsenoside Rg1 increases SOD activity remains unclear.

Both irradiation and oxidative stress induce DNA damage, which is a common mediator of cellular senescence ${ }^{[19]}$; therefore, we examined the levels of DNA damage in these cells. The comet assay, a sensitive technique to analyze DNA damage, has been used in radiation studies of all cell types ${ }^{[20]}$. The comet tail length and the Olive moment are the two main parameters to evaluate DNA damage. At low doses of radiation, a linear relationship occurs between the tail length and the amount of DNA damage; however, at high doses of radiation, the level of DNA damage is related to the Olive moment $^{[21]}$.

Using comet assay analysis, we found that irradiation significantly increased the comet tail length and the Olive moment, while the injection of ginsenoside Rg1 reduced these parameters. These results suggest that ginsenoside Rg1 is able to reduce the levels of DNA damage induced by irradiation. Studies have shown that radiation-induced damage and oxidative stress are closely related. Cytoplasmic irradiation can result in damage to nuclear DNA, and experiments with free radical scavengers have shown that this DNA damage is dependent on ROS generation ${ }^{[22,23]}$. We propose that ginsenoside Rg1 might reduce DNA damage by increasing SOD activity, leading to reduced oxidative stress.

\section{The effect of ginsenoside Rg1 on the expression of P16 ${ }^{\text {INK4a }}$ and} $\mathrm{P} 21^{\mathrm{Cip} 1 / \text { Waf1 }}$ and cell cycle progression

Cell senescence is mediated through several signal transduction pathways, including the $\mathrm{p} 16^{\mathrm{INK} 4}-\mathrm{Rb}$ pathway and the P19 Arf-Mdm2-p53-p21 ${ }^{\text {Cip1/Waf1 }}$ pathway. P16 ${ }^{\text {INK4 }}$ and P21 $1^{\text {Cip1/Waf1, }}$ which are inhibitors of cyclin-dependent kinases (CDK), are in key positions to regulate cellular senescence due to their regulation of the cell cycle ${ }^{[24,25]}$.

P16 prevents cells from escaping $G_{1}$ phase by binding CDK4 to inhibit the assembly of the cyclin D-CDK complex, and expression of P16 is significantly higher in aged cells ${ }^{[26]}$. It has been reported that $\mathrm{p} 16^{\text {INK4a }}$ gene delivery to young cells induced a senescent phenotype, while $\mathrm{p} 16^{\text {INK4a }}$ knockout HSCs and neural stem cells exhibited delaying aging and enhanced function $^{[27]}$.

P21 inhibits the phosphorylation of the cyclin D-CDK4 and cyclin E-CDK2 complexes, resulting in the dephosphorylation of the $\mathrm{Rb}$ protein and the inhibition of E2F release and DNA synthesis ${ }^{[28,29]}$. P21 also binds to PCNA, a cofactor of DNA polymerase, to form the P21-PCNA complex. This complex prevents the polymerase from extending, thereby causing the polymerase to deviate from the templates and results in DNA replication inhibition ${ }^{[30]}$. Above all, P21 prevents cells from entering $S$ phase, during which DNA synthesis occurs. As a result of the overexpression of P21, cells are arrested in $G_{1}$ phase, and cell senescence is induced.

A previous study showed that ginsenoside Rg1 pretreatment significantly reduced the t-BHP-induced increase in P16 and P21 expression in human WI-38 diploid fibroblast cells ${ }^{[31]}$. Similarly, we observed an obvious increase in P16 ${ }^{\text {INK4a }}$ and P21 $1^{\text {Cip1/Waf1 }}$ expression in the Sca- $1^{+}$HSC/HPCs after irradiation; however, daily injection of ginsenoside Rg1 remarkably attenuated these changes.

Both $\mathrm{P} 16^{\mathrm{INK} 4}$ and $\mathrm{P} 21^{\mathrm{Cip} 1 / \text { Waf1 }}$ are important in the regulation of the cell cycle $\mathrm{e}^{[24,25]}$, which is closely related to cell senescence. The cell cycle is an ordered set of events consisting of four phases: $G_{1}, S, G_{2}$ and $M$. One of the hallmarks of aging cells is that they sustain metabolism but gradually lose mitosis reactivity and DNA synthesis activity, resulting in their arrest in $\mathrm{G}_{1}$ phase without entering $S$ phase $\mathrm{e}^{[11]}$. Our cell cycle analysis showed that ginsenoside Rg1 significantly reversed the $G_{1}$ arrest induced by irradiation. This suggests that ginsenoside Rg1 can regulate the expression of $\mathrm{P} 16^{\text {INK4a }}$ and P21 $1^{\text {Cip1/Waf1, }}$ thereby propelling $G_{1}$ phase cells to reenter $S$ phase and delay 
HSC/HPCs senescence.

\section{Conclusion}

Our study showed that ginsenoside Rg1 could improve the resistance of hematopoietic stem/progenitor cells to radiationinduced senescence using an in vivo mice model. We propose that ginsenoside Rg1 exerts anti-aging effects through its anti-oxidant properties, which can relieve the DNA damage induced by chronic oxidative stress and reduce the expression of $\mathrm{P} 16^{\mathrm{INK} 4 \mathrm{a}}$ and $\mathrm{P} 21^{\mathrm{Cip} 1 / \text { Wafl }}$ to propel the Sca1 ${ }^{+}$cells in $\mathrm{G}_{1}$ phase into $S$ phase. Ginsenoside Rg1 cannot prevent cellular damage induced by irradiance but instead exerted an anti-oxidative effect by rescuing SOD activity to delay senescence. The present study may provide a theoretical and experimental foundation for the application of ginsenoside Rg1 in delaying cellular senescence.

\section{Acknowledgements}

This study was supported by the National Natural Science Foundation of China, № 81173398, 30973818, 30970872, and 81202785.

\section{Author contribution}

Cui CHEN, Jian-wei WANG, and Ya-ping WANG designed the research; Yue ZHOU, Ke SHUN, Shan GENG, and Jun LIU performed the research; Jie CHEN and Tin-yu LI analyzed the data; Cui CHEN, Xin-Yi MU, and Ya-Ping WANG wrote the paper.

\section{References}

1 Rossi DJ, Bryder D, Zahn JM, Ahlenius H, Sonu R, Wagers AJ, et al. Cell intrinsic alterations underlie hematopoietic stem cell aging. Proc Natl Acad Sci U S A 2005; 102: 9194-9.

2 Rossi DJ, Bryder D, Weissman IL. Hematopoietic stem cell aging: mechanism and consequence. Exp Gerontol 2007; 42: 385-90.

3 Gazit R, Weissman H, Rossl DJ. Hematopoietic stem cells and the aging hematopoietic system. Strain Hematol 2008; 45: 218-23.

4 Chambers SM, Goodell MA. Hematopoietic stem cell aging: wrinkles in stem cell potential. Stem Cell Rev 2007; 3: 201-11.

5 Cheng Y, Shen LH, Zhang JT. Anti-amnestic and anti-aging effects of ginsenoside Rg1 and Rb1 and its mechanism of action. Acta Pharmacol Sin 2005; 26: 143-9.

6 Chen X, Zhang J, Fang Y, Zhao C, Zhu Y. Ginsenoside Rg1 delays tertbutyl hydroperoxide-induced premature senescence in human WI38 diploid fibroblast cells. J Gerontol A Biol Sci Med Sci 2008; 63: 253-64.

7 Wang Y, Schulte BA, LaRue AC, Ogawa M, Zhou D. Total body irradiation selectively induces murine hematopoietic stem cell senescence. Blood 2006; 107: 358-66.

8 Wang Y, Liu L, Pazhanisamy SK, Li H, Meng A, Zhou D. Total body irradiation causes residual bone marrow injury by induction of persistent oxidative stress in murine hematopoietic stem cells. Free Radic Biol Med 2010; 48: 348-56.

9 Zhou Y, Yang B, Yao X, Wang YP. Establishment of an aging model of Sca- $1^{+}$hematopoietic stem cell and studies on its relative biological mechanisms. In Vitro Cell Dev Biol Anim 2011; 47: 149-56.

10 Dimri GP, Lee X, Basile G, Acosta M, Scott G, Roskelley C, et al. A biomarker that identifies senescent human cells in culture and in aging skin in vivo. Proc Natl Acad Sci U S A 1995; 92: 9363-7.

11 Stein GH, Beeson M, Gordon L. Failure to phosphorylate the retino- blastoma gene produce in senescent human fibroblasts. Science 1990; 249: 666-9

12 Kamminga LM, van Os R, Ausema A, Noach EJ, Weersing E, Dontje $B$, et al. Impaired hematopoietic stem cell functioning after serial transplantation and normal aging. Stem Cells 2005; 23: 82-92.

13 Jang YY, Sharkis SJ. A low level of reactive oxygen species selects for primitive hematopoietic stem cells that may re-side in the lowoxygenic niche. Blood 2007; 110: 3056-63.

14 Ito K, Hirao A, Arai F, Matsuoka S, Takubo K, Hamaguchi I, et al. Regulation of oxidative stress by ATM is required for self-renewal of haematopoietic stem cells. Nature 2004; 431: 997-1002.

15 Ito K, Hirao A, Arai F, Takubo K, Matsuoka S, Miyamoto K, et al. Reactive oxygen species act through p38 MAPK to limit the lifespan of hematopoietic stem cells. Nat Med 2006; 12: 446-51.

16 Chen XC, Zhou YC, Chen Y, Zhu YG, Fang F, Chen LM. Ginsenoside Rg1 reduces MPTP-induced substantia nigra neuron loss by suppressing oxidative stress. Acta Pharmacol Sin 2005; 26: 56-62.

17 Korivi M, Hou CW, Huang CY, Lee SD, Hsu MF, Yu SH, et al. Ginsenoside-Rg1 protects the liver against exhaustive exerciseinduced oxidative stress in rats. Evid Based Complement Alternat Med 2012; 2012: 932165.

18 Shen L, Han JZ, Li C, Yue SJ, Liu Y, Qin XQ, et al. Protective effect of ginsenoside Rg1 on glutamate-induced lung injury. Acta Pharmacol Sin 2007; 28: 392-7.

19 Chen JH, Hales CN, Ozanne SE. DNA damage, cellular senescence and organismal ageing: causal or correlative? Nucleic Acids Res 2007; 35: 7417-28.

20 Fairbairn DW, Olive PL, Oneill KL. The comet assay: a comprehensive review. Mutation Res 1995; 339: 37-59.

21 Olive PL, Durand RE. Heterogeneity in DNA damage using the comet assay. Cytometry A 2005; 66: 1-8.

22 Spitz DR, Azzam EI, Li JJ, Gius D. Metabolic oxidation/reduction reactions and cellular responses to ionizing radiation: a unifying concept in stress response biology. Cancer Metastasis Rev 2004; 23 : 311-22.

23 Wu LJ, Randers-Pehrson G, Xu A, Waldren CA, Geard CR, Yu Z, et al. Targeted cytoplasmic irradiation with alpha particles induces mutations in mammalian cells. Proc Natl Acad Sci U S A 1999; 96: 4959-64.

24 Morisaki H, Ando A, Nagata Y, Pereira-Smith O, Smith JR, Ikeda K, et al. Complex mechanisms underlying impaired activation of Cdk4 and Cdk2 in replicative senescence: roles of p16, p21, and cyclin D1. Exp Cell Res 1999; 253: 503-10.

25 Gerland LM, Ffrench M, Magaud JP. Cyclin dependent kinase inhibitors and replicative senescence. Pathol Biol 2001; 49: 830-9.

26 Ohtani N, Zebedee Z, Huot TJ, Stinson JA, Sugimoto M, Ohashi Y, et al. Opposing effects of Ets and Id proteins on p16INK4a expression during cellular senescence. Nature 2001; 409: 1067-70.

27 Janzen V, Forkert R, Fleming HE, Saito Y, Waring MT, Dombkowski $\mathrm{DM}$, et al. Stem-cell ageing modified by the cyclin-dependent kinase inhibitor p16 ${ }^{\mathrm{INK} 4 \mathrm{a}}$. Natue 2006; 443: 421-6.

28 Harper JW, Adami GR, Wei N, Keyomarsi K, Elledge SJ. The p21 Cdkinteracting protein Cip1 is a potent inhibitor of $\mathrm{G}_{1}$ cyclin-dependent kinases. Cell 1993; 75: 805-16.

29 Sandhu C, Donovan J, Bhattacharya N, Stampfer M, Worland P, Slingerland J. Reduction of Cdc25A contributes to cyclin E1-Cdk2 inhibition at senescence in human mammary epithelial cells. Oncogene 2000; 19: 5314-23.

30 Sherr CJ. $G_{1}$ phase progression: cycling on cue. Cell 1994; 79: 551-5.

31 Chen XC, Zhu YG, Zhu LA, Huang C, Chen Y, Chen LM, et al. Ginsenoside Rg1 attenuates dopamine-induced apoptosis in PC12 cells by suppressing oxidative stress. Eur J Pharmacol 2003; 473: 1-7. 